\title{
ANALISIS SETTING RELE OGS SEBAGAI SISTEM PENGAMAN TRANSFORMATOR 3 UNTUK MENJAGA KONTINYUITAS ALIRAN DAYA DI GARDU INDUK PESANGGARAN
}

\author{
I Wayan Alit Wigunawan ${ }^{1}$, I Gede Dyana Arjana ${ }^{2}$, Cok Gede Indra Partha ${ }^{3}$ \\ ${ }_{1,2,3}$ Program Studi Teknik Elektro, FakultasTeknik,Universitas Udayana \\ Email : alitwigunawan@yahoo.co.id ${ }^{1}$, dyanaarjana@unud.ac.id ${ }^{2}$, cokindra@unud.ac.id $^{3}$
}

\begin{abstract}
ABSTRAK
Transformator 3 di GI Pesanggaran mendapat penambahan pembangkit dengan daya maksimum $60 \mathrm{MW}$. Daya pembangkit digunakan untuk mensuplai beban penyulang di GI Pesanggaran dan juga disalurkan ke sistem transmisi $150 \mathrm{kV}$ di Gl Pesanggaran melalui Transformator 3 menuju GI Nusa Dua untuk membantu suplai daya di GI Nusa Dua. Jika terjadi gangguan penyulang di GI Pesanggaran yang menyebabkan beban penyulang terputus, maka daya dari pembangkit yang dialirkan ke sistem $150 \mathrm{kV}$ bertambah. Sehingga Transformator 3 bekerja lebih berat, yang berakibat arus dan suhu pada transformator juga meningkat. Meningkatnya suhu pada transformator dalam jangka waktu lama dapat mengakibatkan kerusakan dan berkurangnya lifetime transformator. Dari permasalahan tersebut maka dilakukan analisis perhitungan setting arus dan waktu kerja OGS dan OCR sebagai sistem pengaman Transformator 3. Hasil dari perhitungan setting arus OGS tahap 1 adalah $1600 \mathrm{~A}$ dengan setting waktu kerja 2 detik, tahap 2 adalah 1700 A dengan setting waktu kerja 1,5 detik dan tahap 31800 A dengan setting waktu kerja 1 detik. Karakteristik rele OGS adalah definite. Untuk OCR di sisi $150 \mathrm{kV}$ diperoleh setting arus 277 A dan setting waktu 1,36 detik, sedangkan setting OCR di sisi $20 \mathrm{kV}$ didapat setting arus 2078,4 A dan setting waktu kerja 1,18 detik dengan karakteristik rele OCR yang digunakan adalah inverse.
\end{abstract}

Kata Kunci : OGS (Over Generator Shedding), OCR (Over Current Relay), Transformator.

\begin{abstract}
Transformer 3 of Pesanggaran Substation obtains additional power plants with a maximum power of $60 \mathrm{MW}$. Power generation is used to supply the load of feeders in Substation of Pesanggaran and also channeled to $150 \mathrm{kV}$ transmission system at Substation of Pesanggaran through Transformator 3 to Substation of Nusa Dua to assist power supply at Nusa Dua Substation. If there is a feeders interruption in the Substation of Pesanggaran which causes the load of feeders to be disconnected, then the power from the generator that is flowed to the 150 $k V$ system increases. Thus the Transformer 3 works heavier, resulting in the current and temperature of the transformer also increased. Increased temperatures in the transformer for long periods can result in damage and reduced lifetime of the transformer. From the problems then calculation of current and working time OGS and OCR as the Transformer 3 safety system. The result of calculation of OGS setting of phase1 is 1600 A with setting work time of 2 seconds, phase 2 is $1700 \mathrm{~A}$ with setting working time of 1,5 seconds and stage 3 of $1800 \mathrm{~A}$ with setting work time of 1 second. The OGS relay characteristic is definite. For OCR at $150 \mathrm{kV}$ side, the current setting is $277 \mathrm{~A}$ and setting time is 1.36 seconds, while OCR setting at $20 \mathrm{kV}$ side is obtained by setting current of 2078.4 A and setting time of 1.18 seconds with OCR Relay characteristic used is inverse.
\end{abstract}

Keywords: OGS (Over Generator Shedding), OCR (Over Current Relay), Transformer.

\section{PENDAHULUAN}

PT. PLN (Persero) sebagai perusahaan yang mensuplai energi listrik berupaya meningkatkan suplai daya di daerah Nusa Dua, karena terbatasnya lahan di GI Nusa Dua sehingga tidak terdapat tempat untuk menempatkan pembangkit baru. Sehingga penambahan 
daya dilakukan pada GI Pesanggaran karena GI Pesanggaran merupakan salah satu GI yang mensuplai daya listrik untuk Gardu Induk Nusa Dua.

Penambahan 4 blok pembangkit dengan kapasitas maksimum 60 MW dilakukan pada sistem Transformator 3 di GI Pesanggaran. Ketika beban pada penyulang $20 \mathrm{kV}$ di GI Pesanggaran trip karena gangguan atau kelebihan beban pada penyulang, maka beban penyulang yang menyerap daya pembangkit akan berkurang. Berkurangnya beban penyulang yang menyerap daya dari pembangkit akan menyebabkan suplai daya dari pembangkit yang mengalir ke sistem $150 \mathrm{kV}$ melalui Transformator 3 menuju GI Nusa Dua menjadi lebih besar. Besarnya daya dari pembangkit yang dialirkan ke sistem 150 $\mathrm{kV}$ akan menyebabkan transformator 3 juga akan bekerja lebih berat yang menyebabkan arus yang mengalir pada transformator juga meningkat, akibatnya terjadi kenaikan suhu pada unit transformator yang dapat menyebabkan kerusakan dan berkurangnya masa pakai transformator.

Berdasarkan permasalahan tersebut maka dilakukan analisis sistem OGS (over generator shedding) yang dipasang pada sistem distribusi $20 \mathrm{kV}$ di Gardu Induk Pesanggaran. OGS adalah rele arus lebih dengan karakteristik definite yang bekerja dengan membaca besaran arus yang mengalir masuk ke transformator. Jika terjadi aliran arus yang melebihi arus setting dari OGS, maka OGS akan bekerja sesuai waktu kerja yang telah di-setting untuk membatasi daya yang disuplai unit pembangkit. Sehingga diharapkan setelah daya dari pembangkit dikurangi maka transformator yang tadinya mengalami kelebihan beban akan kembali normal. Sehingga kontinyuitas aliran daya di GI Pesanggaran tetap terjaga dengan baik.

\section{KAJIAN PUSTAKA}

\subsection{TRANSFORMATOR TENAGA}

Transformator tenaga adalah suatu peralatan tenaga listrik yang tidak mempunyai bagian yang bergerak, berfungsi untuk menyalurkan daya yang dibutuhkan ke beban dengan rugi-rugi minimum pada frekuensi fundamentalnya [1]. Untuk mentransfer energi listrik menggunakan transformator dapat dilakukan dari satu rangkain ke rangkaian lain tanpa melalui hubungan fisik diantara dua rangkaian. Transfer daya tersebut dilakukan sepenuhnya oleh rangkaian medan magnet. Penggunaan transformator dalam sistem tenaga listrik memungkinkan terpilihnya tegangan yang sesuai dan ekonomis untuk tiap-tiap keperluan, misalnya kebutuhan akan tegangan tinggi dalam pengiriman daya listrik jarak jauh. Berdasarkan tegangan operasinya dapat dibedakan menjadi transformator transmisi mengubah tegangan tinggi dari $150 \mathrm{kV}$ menjadi tegangan menengah $20 \mathrm{kV}$, sedangkan trafo distribusi mengubah tegangan menengah $20 \mathrm{kV}$ menjadi tegangan rendah 380/220 Volt yang selanjutnya disalurkan melalui jaringan tegangan rendah (JTR) ke konsumen satu phasa atau tiga phasa [2]. Komponen utama transformator tenaga terdiri dari bagian-bagian diantaranya inti besi, kumparan transformator, minyak transformator, bushing, tangki konservator, peralatana Bantu pendinginan transformator, tap changer dan alat pernapasan (dehydrating breather) [3].

\subsection{Prinsip Kerja Rele arus lebih (OCR)}

Rele arus lebih merupakan salah satu sistem proteksi yang berfungsi melindungi sistem jika terjadi gangguan. Rele arus lebih bekerja dengan membaca input berupa besaran arus kemudian membandingankan dengan nilai setting, apabila nilai arus yang terbaca oleh rele melebihi nilai setting, maka rele akan mengirim perintah trip (lepas) kepada pemutus tenaga (PMT) atau Circuit Breaker (CB) setelah waktu tunda yang diterapkan pada setting. Rele ini digunakan untuk mengamankan peralatan terhadap gangguan hubung singkat antar fasa, hubung singkat satu fasa ke tanah dan beberapa hal dapat digunakan sebagai pengaman beban lebih [4]. Pada dasarnya batas setting rele arus lebih adalah rele tidak boleh bekerja pada saat beban maksimum. Setting arusnya harus lebih besar dari pada arus beban maksimumnya [5]. Salah satu pengaplikasian dari Rele arus lebih (OCR) adalah membatasi arus dari pembangkit atau sering disebut Over Generator Shedding (OGS). Namun pada OGS memiliki setting yang sedikit berbeda dengan setting OCR pada umumnya, yang membedakan setting OCR dan OGS adalah pada setting waktunya. Berdasarkan karakteristiknya, rele arus lebih ini dapat dibagi menjadi 3 yaitu : 
1. Rele arus lebih seketika (Instantaneous)

2. Rele arus lebih waktu tertentu (Definite Time)

3. Rele arus lebih waktu terbalik (Inverse Time)

\subsubsection{Perhitungan Setting Rele Arus Lebih}

Arus setting untuk rele arus lebih, baik dari sisi primer maupun sekunder trafo tenaga dapat dihitung menggunakan Persamaan (1) [6].

$$
I_{\text {set }}=\frac{K_{f k}}{K_{d}} \times I_{\text {nom }}
$$

Arus nominal pada perangkat yang diamankan dapat dihitung menggunakan Persamaan (2).

$$
I_{\text {nom }} \frac{S}{\sqrt{3} \times V}
$$

Nilai $K_{d}$ untuk rele arus lebih mempunyai nilai 1,0 . Untuk Nilai $K_{\mathrm{fk}}$ rele arus lebih dengan karakteristik rele waktu terbalik (inverse) di-set sebesar 1,05-1,2 x $I_{\text {nom, dan untuk rele dengan karakteristik }}$ waktu arus tertentu (definite) di-set sebesar $0,8-1,1 \times I_{\text {nom }}[6]$.

\subsubsection{Perhitungan Setting Waktu Tunda}

Nilai waktu tunda $\left(\mathrm{t}_{\mathrm{d}}\right)$ dapat dicari dengan besarnya arus hubung singkat $\left(\mathrm{I}_{\mathrm{f}}\right)$, Penyetelan/setting arusnya $\left(I_{\text {set }}\right)$, dan kurva karakteristik rele yang dipakai. Persamaan (3) digunakan untuk mencari nilai waktu tunda $\left(\mathrm{t}_{\mathrm{d}}\right)$ rele [7].

$$
t_{d}=\frac{\left({ }^{I f} / \text { Iset }\right)^{\alpha}-1}{\beta} \times t
$$

Nilai waktu aktual rele bekerja terhadap gangguan maksimum dapat dapat dihitung menggunakan Persamaan (4).

$$
t=\frac{\beta}{\left(\frac{I_{f}}{I_{\text {set }}}\right)^{\alpha}-1} \times t_{d}
$$

Waktu kerja dari rele arus lebih juga berdasarkan dari tipe kurva alat tersebut. Untuk tabel kurva waktu kerja dapat dilihat pada tabel 1 berikut.

Tabel 1. Konstanta Perhitungan Waktu Tunda Rele Arus Lebih Waktu Terbalik [7]

\begin{tabular}{|l|c|c|}
\hline Tipe Kurva & $\boldsymbol{\alpha}$ & $\boldsymbol{\beta}$ \\
\hline IEC Standart Inverse & 0,02 & 0,14 \\
\hline IEC Very Inverse & 1,0 & 13,50 \\
\hline IEC Extremely Inverse & 2.0 & 80,00 \\
\hline
\end{tabular}

\subsection{Arus Hubung Singkat}

Arus hubung singkat dapat diakibatkan oleh gangguan dari luar maupun dari dalam jaringan. Sebelum menghitung nilai gangguan hubung singkat diperlukan nilai impedansi sumber dan impedansi trafo. Impedansi sumber dapat dihitung dengan data hubung singkat pada bus primer trafo menggunakan Persamaan (4).

$$
z_{h s}=\frac{V_{p} \times 1000}{\sqrt{3} \times I_{f}}
$$

Perhitungan Impedansi transformator yang digunakan adalah nilai reaktansinya, sedangkan tahananya diabaikan karena nilainya kecil. Nilai reaktansi dari transformator dalam Ohm dapat dihitung dengan Persamaan (5).

$$
z_{t r}=\frac{V_{p}{ }^{2} \times z_{t}}{S}
$$

Gangguan hubung singkat yang dapat terjadi pada jaringan sistem kelistrikan ada 3, Gangguan hubung singkat 3 fasa, Gangguan hubung singkat antar fasa, dan Gangguan hubung singkat 1 fasa ke tanah[8].

Gangguan hubung singkat 3 fasa ada dua yaitu Gangguan hubung singkat 3 fasa 150 kV dan 20 kV. Nilai Gangguan hubung singkat 3 fasa $150 \mathrm{kV}$ dapat dihitung dengan Persamaan (6).

$$
I_{3 \emptyset(150)}=\frac{V_{p \times 10^{3}}}{\sqrt{3} \times\left(Z_{h s+} Z_{t r}\right)}
$$

Nilai Gangguan hubung singkat 3 fasa 20 kV dapat dihitung dengan Persamaan (7).

$$
I_{3 \emptyset(20)}=I_{3 \emptyset(20)} \times \frac{V_{p}}{V_{s}}
$$

Gangguan hubung singkat antar fasa ada dua yaitu Gangguan hubung singkat antar fasa $150 \mathrm{kV}$ dan $20 \mathrm{kV}$. Nilai Gangguan hubung singkat antar fasa 150 $\mathrm{kV}$ dapat dihitung dengan Persamaan (8).

$$
\frac{\sqrt{3}}{2} \times I_{3 \emptyset}(150)
$$

Nilai Gangguan hubung singkat antar fasa $20 \mathrm{kV}$ dapat dihitung dengan Persamaan (9).

$$
\frac{\sqrt{3}}{2} \times I_{3 \emptyset}(20)
$$


Nilai Gangguan hubung singkat 1 fasa ke tanah dapat dihitung dengan Persamaan (10).

$$
\frac{V_{S} \times 1000}{\sqrt{3} \times N G R}
$$

\subsection{Over Generator Shedding (OGS)}

OGS adalah suatu skema pembatasan pembangkit yang mana diterapkan pada suatu rele yang akan menjalankan skema untuk mengatur/mengamankan arus yang masuk ke peralatan agar tidak melebihi pengaman saluran dengan mentrip-kan pembangkit atau membuka PMT. Pembangkit tenaga listrik pada suatu sitem tenaga seringkali mendapat gangguan yang tidak dapat dihindari, misalnya dengan terjadinya trip pada penyulang secara tibatiba karena ada beban melebihi kapasitas dibebankan ke sistem atau dapat juga dengan terjadinya gangguan akibat putusnya penghantar akibat gangguan alam. Inputan yang menjadi acuan OGS untuk bekerja adalah arus [9].

\section{METODOLOGI PENELITIAN}

Proses pertama dalam penelitian adalah melakukan pengumpulan data kelistrikan di Gardu Induk Pesanggaran yaitu data Single Line Diagram, Kapasitas Pembangkit Terpasang, data spesifikasi Transformator 3 , dan data jenis pengaman Transformator 3. Proses selanjutnya adalah melakukan perhitungan arus hubung singkat 3 fasa, antar fasa pada sisi $150 \mathrm{kV}$ dan $20 \mathrm{kV}$. Langkah berikutnya adalah melakukan analisis perhitungan setting arus dan waktu kerja OGS di Transformator 3. Dari perhitungan hubung singkat yang didapat selanjutnya dilakukan analisis perhitungan setting arus dan waktu kerja rele arus lebih di sisi primer $150 \mathrm{kV}$, dan di sisi sekunder 20 kV pada Transformator 3. Kemudian menentukan koordinasi setting OGS dan OCR pada Transformator 3 untuk mengamankan Transformator 3 di Gardu Induk Pesanggaran.

\section{HASIL DAN PEMBAHASAN}

4.1 Gambaran Umum Transformator 3 di GI Pesanggaran

Di Gardu Induk Pesanggaran terdapat Transformator 3 dengan spesifikasi yang dapat dilihat pada tabel 2 .

Tabel 2 Data Transformator 3 di GI Pesanggaran

\begin{tabular}{|c|l|c|}
\hline No & \multicolumn{1}{|c|}{ Spesifikasi } & Transformator \\
\hline 1 & Merk & UNINDO \\
\hline 2 & Daya (S) & $60 \mathrm{MVA}$ \\
\hline 3 & Tegangan & $\begin{array}{c}\mathrm{Vp}=150 \mathrm{kV} \\
\mathrm{Vs}=20 \mathrm{kV}\end{array}$ \\
\hline 4 & Impedansi (Zt) & $0,1243 \mathrm{pu}$ \\
\hline 5 & Resistansi NGR & $40 \Omega$ \\
\hline 6 & Trafo Arus & $\begin{array}{c}\mathrm{CTp}=300 / 5 \\
\mathrm{CT}\end{array}=2000 / 5$ \\
\hline 7 & $\begin{array}{l}\text { Arus Nominal } \\
\text { Trafo }\end{array}$ & $\begin{array}{c}\text { Ip }=230,94 \mathrm{~A} \\
\text { Is }=1732 \mathrm{~A}\end{array}$ \\
\hline 8 & Nilai Ihs total & Ihs $=9,737 \mathrm{kA}$ \\
\hline
\end{tabular}

Transformator 3-60 MVA di GI Pesanggaran mendapat suplai daya listrik dari 4 blok pembangkit yaitu PLTD Blok C1A, C1B, C3 dan PLTD D2 dengan daya maksimum sebesar $60 \mathrm{MW}$. Daya dari 4 blok pembangkit tersebut disalurkan menuju Transformator 3 lalu masuk ke sistem $150 \mathrm{kV}$ setelah itu daya listrik masuk ke Gardu Induk Nusa Dua untuk membantu suplai daya di GI Nusa Dua, selain itu daya dari pembangkit juga digunakan untuk mensuplai beban penyulang pada sistem distribusi 20 kV di Gl Pesanggaran. Gambar single line diagram Transformator 3 dapat dilihat pada gambar 1 berikut.

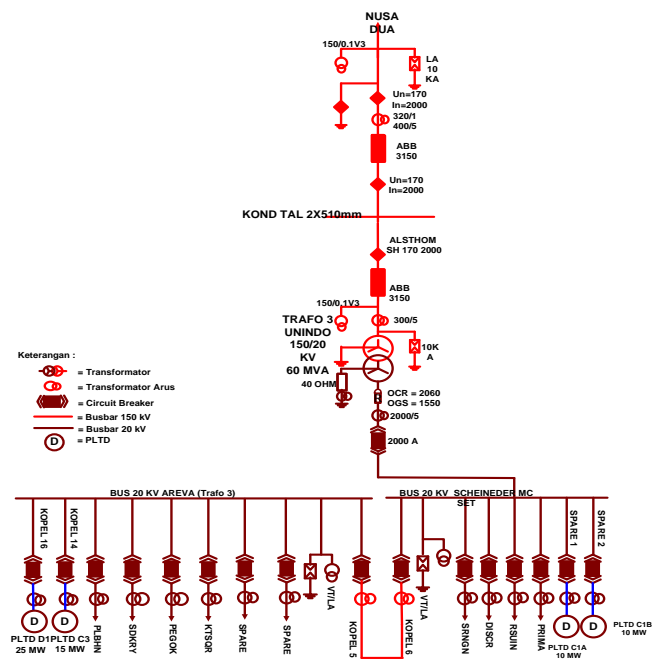

Gambar 1. Single Line Diagram Transformator 3

\subsection{Menghitung Impedansi Sumber dan Impedansi Trafo Tenaga}

Impedansi sumber dapat dihitung dengan data hubung singkat pada bus primer trafo menggunakan Persamaan (4) sebagai berikut.

$$
\begin{aligned}
z_{\text {hs }} & =\frac{V_{p} \times 1000}{\sqrt{3} \times I_{f}} \\
& =\frac{150 \times 1000}{\sqrt{3} \times 9,737} \\
& =8,894 \Omega
\end{aligned}
$$


Perhitungan besar impedansi transformator dapat dihitung menggunakan Persamaan (5) sebagai berikut.

$$
\begin{aligned}
Z \operatorname{trf} & =\frac{V_{p}{ }^{2} \times Z_{t}}{S} \\
& =\frac{150^{2} \times 0,1243}{60000} \\
& =46,612 \Omega
\end{aligned}
$$

4.3 Arus Hubung Singkat 3 Phasa, 2 Phasa, dan 1 Phasa ke Tanah

Arus gangguan yang akan dihitung dalam penelitian ini adalah arus hubung singkat antar 3 fasa, antar 2 fasa dan hubung singkat 1 fasa-tanah.

Nilai Gangguan hubung singkat 3 fasa $150 \mathrm{kV}$ dapat dihitung dengan Persamaan (6) sebagai berikut.

$$
\begin{aligned}
I_{\mathrm{hs} 3 \varnothing(150)}= & \frac{V_{p} \times 10^{3}}{\sqrt{3} \times\left(Z_{h s}+Z_{t r}\right)} \\
& =\frac{150 \times 1000}{\sqrt{3} \times(8,894+46,612)} \\
& =1560 \mathrm{~A}
\end{aligned}
$$

Nilai Gangguan hubung singkat 3 fasa $20 \mathrm{kV}$ dapat dihitung dengan Persamaan (7) sebagai berikut.

$$
\begin{aligned}
I_{3 \varnothing(20)} & =I_{3 \varnothing(20)} \times \frac{V_{p}}{V_{s}} \\
= & 1560 \times \frac{150}{20} \\
= & 11700 \mathrm{~A}
\end{aligned}
$$

Nilai Gangguan hubung singkat antar fasa $150 \mathrm{kV}$ dapat dihitung dengan Persamaan (8).sebagai berikut.

$$
\begin{aligned}
& \frac{\sqrt{3}}{2} \times I_{3 \emptyset}(150) \\
= & \frac{1,732}{2} \times 1560 \\
= & 1350,96 \mathrm{~A}
\end{aligned}
$$

Nilai Gangguan hubung singkat antar fasa $20 \mathrm{kV}$ dapat dihitung dengan Persamaan (9) sebagai berikut.

$$
\begin{aligned}
& \frac{\sqrt{3}}{2} \times I_{3 \varnothing(20)} \\
= & \frac{1,732}{2} \times 1350,96 \mathrm{~A} \\
= & 10132,2 \mathrm{~A}
\end{aligned}
$$

Nilai Gangguan hubung singkat 1 fasa ke tanah dapat dihitung dengan Persamaan (10) sebagai berikut.

$$
\frac{V_{s} \times 1000}{\sqrt{3} \times N G R}
$$

$$
\begin{aligned}
& =\frac{20 \times 1000}{\sqrt{3} \times 40} \\
& =288,675 \mathrm{~A}
\end{aligned}
$$

Berdasarkan hasil perhitungan, diperoleh nilai arus hubung singkat seperti ditunjukkan pada tabel 3.

Tabel 3 Data Hasil Perhitungan Arus

Hubung Singkat Pada Transformator 3

\begin{tabular}{|c|c|c|}
\hline No & Perhitungan & Transformator 3 \\
\hline 1 & $\mathrm{I}_{3 \varnothing(150)}$ & $1560 \mathrm{~A}$ \\
\hline 2 & $\mathrm{I}_{2 \varnothing(150)}$ & $1350,96 \mathrm{~A}$ \\
\hline 3 & $\mathrm{I}_{3 \varnothing(20)}$ & $11700 \mathrm{~A}$ \\
\hline 4 & $\mathrm{I}_{2 \varnothing(20)}$ & $10132,2 \mathrm{~A}$ \\
\hline 5 & $\mathrm{I}_{1 \varnothing(20)}$ & $288,675 \mathrm{~A}$ \\
\hline
\end{tabular}

\subsection{Analisis Perhitungan Setting OGS} Pada Transformator 3 di Gardu Induk Pesanggaran

Gangguan yang terjadi pada penyulang di Gardu Induk Pesanggaran akan menyebabkan daya dari pembangkit tidak terserap oleh beban sehingga daya dari pembangkit yang mengalir ke Transformator 3 akan semakin besar yang menyebabkan Transformator 3 bekerja melebihi kapasitas operasinya yang menurut PT. PLN (persero) adalah sebesar $85 \%$. Untuk penentuan setting arus OGS adalah 1,1 dikalikan dengan arus operasi trafo. Untuk perhitungan setting OGS akan dibagi menjadi 3 tahap sebagai berikut :

Berdasarkan persamaan (2), didapat arus nominal transformator 3 sebagai berikut.

$$
\begin{gathered}
I_{\text {nom }}=\frac{60000 \mathrm{kVA}}{\sqrt{3} \times 20 \mathrm{kV}} \\
=\frac{60000}{34,64} \\
=1732 \mathrm{~A}
\end{gathered}
$$

Untuk setting arus OGS tahap 1 untuk batas kerja operasi trafo $85 \%$ yaitu :

Batas operasi trafo $85 \%=I_{\text {nom }}$ trafo $\times 85 \%$

$$
\begin{aligned}
& =1732 \mathrm{~A} \times 85 \% \\
& =1472 \mathrm{~A}
\end{aligned}
$$

Berdasarkan persamaan 1, didapat setting arus OGS sebagai berikut :

$$
\begin{aligned}
\text { Isogs } & =\frac{1,1}{1} \times 1472 \\
& =1619 \mathrm{~A} \text { dipilih, } \\
\text { Iset } & =1600 \mathrm{~A} \\
\text { Isogs } 1 & =\frac{1600}{2000 / 5} \\
& =4 \text { dipilih, } \\
& =4 \mathrm{~A}(\text { setelan pada rele })
\end{aligned}
$$


Dengan cara yang sama dapat ditentukan setting OGS untuk tahap 2 dengan batas operasi transformator $90 \%$ dan tahap 3 dengan batas operasi transformator $95 \%$ yang ditunjukkan tabel 4 berikut :

Tabel 4 Setting Arus Dan Waktu Kerja OGS

\begin{tabular}{|l|c|c|c|}
\hline Setting OGS & Tahap 1 & Tahap 2 & Tahap 3 \\
\hline Iset $(\mathrm{A})$ & 1600 & 1700 & 1800 \\
\hline Iset rele $(\mathrm{A})$ & 4 & 4,25 & 4,5 \\
\hline T (detik) & 2 & 1,5 & 1 \\
\hline Kurva & Definite & Definite & Definite \\
\hline
\end{tabular}

Sedangkan untuk perhitungan daya yang dibatasi OGS adalah sebagai berikut :

I operasi trafo $85 \%=1732 \mathrm{~A} \times 0,85$

$$
=1472 \mathrm{~A}
$$

Untuk arus yang dibatasi OGS yaitu :

Arus dibatasi OGS $=I_{\text {nom }}$ trafo -1 operasi trafo $85 \%$ $=1732-1472$

$$
=260 \mathrm{~A}
$$

Jadi daya yang dibatasi OGS yaitu :

$$
\begin{aligned}
& P=\sqrt{ } \times V \times I \times \operatorname{Cos} \varphi \\
& P=1,732 \times 20 \times 260 \times 0,85 \\
& P=7,5 \mathrm{MW}
\end{aligned}
$$

Jadi besar daya yang akan dibatasi OGS adalah sebesar 7,5 MW. Sehingga pembangkit yang akan dibatasi di Gl Pesanggaran seperti tabel 5 berikut.

Tabel 5 Target Pembangkit Yang Dibatasi

\begin{tabular}{|l|c|c|c|}
\hline Tahap & $\begin{array}{c}\text { Target Trip } \\
\text { Pembangkit }\end{array}$ & I (A) & P (MW) \\
\hline Tahap 1 & Blok C1A & 86 & 2,5 \\
\hline Tahap 2 & Blok C1B & 86 & 2,5 \\
\hline Tahap 3 & Blok C3 & 86 & 2,5 \\
\hline
\end{tabular}

Dari tabel 4 dan tabel 5 setting arus dan waktu kerja OGS didapat arus kerja OGS sebesar 1600 A dengan waktu kerja 2 detik dan OGS akan mengurangi daya dari Blok Pembangkit C1A sebesar 2,5 MW. Pada tahap 2 OGS didapat arus kerja OGS sebesar 1700 A dengan waktu kerja 1,5 detik dan OGS akan mengurangi daya dari Blok Pembangkit C1B sebesar 2,5 MW. Untuk tahap 3 didapat arus kerja OGS sebesar 1800 A dengan waktu kerja 1 detik dan OGS akan mengurangi daya dari Blok Pembangkit C3 sebesar 2,5 MW. Hal ini dilakukan agar keseimbangan antara daya dari pembangkit yang mensuplai beban tidak terlalu banyak berubah sehingga beban masih dapat menerima suplai daya listrik yang mencukupi.

\subsection{Analisis Perhitungan Setting Rele Arus Lebih Pada Transformator 3 di Gardu Induk Pesanggaran}

Jenis rele yang digunakan pada Transformator 3 Gardu Induk Pesanggaran adalah rele arus lebih dengan karakteristik inverse yang diset dengan nilai 1,2 dikalikan dengan arus nominal Tranformator 3. Setting arus pada rele arus lebih Transformator 3 dihitung menggunakan persamaan (1) adalah :

$$
\begin{aligned}
\text { Isp } & =\frac{1,2}{1} \times 230,94 \mathrm{~A} \\
& =\frac{277}{300 / 5} \\
& =4,62 \text { dipilih } \\
\text { Isp } & =4,6 \mathrm{~A} \text { (setelan pada rele) }
\end{aligned}
$$

Setting waktu rele arus lebih dengan karakteristik inverse pada sisi $150 \mathrm{kV}$ Transformator 3 dihitung menggunakan nilai arus gangguan hubung singkat 3 fasa menggunakan persamaan (3) dan (4) adalah :

$$
\begin{aligned}
& t d=\frac{(1350,96 / 277)^{0,02}-1}{0,14} \times 1,5 \\
& t d=0,34 \mathrm{SI}
\end{aligned}
$$

Jadi waktu kerja aktual rele (t) adalah :

$$
\begin{aligned}
& t=\frac{0,14}{(1560 / 277)^{0,02}-1} \times 0,34 \\
& t=1,36 \text { detik }
\end{aligned}
$$

Dengan cara yang sama dapat ditentukan setting Rele Arus Lebih pada sisi 20 kV pada Transformator 3 yang ditunjukkan tabel 6 berikut.

Tabel 6 Setting Rele Arus Lebih Hasil Perhitungan Pada Sisi $150 \mathrm{kV}$ dan $20 \mathrm{kV}$

\begin{tabular}{|l|c|c|}
\hline Setting & OCR 150 kV & OCR 20 kV \\
\hline CT Rasio & $300 / 5$ & $2000 / 5$ \\
\hline I Set & $277 \mathrm{~A}$ & $2078,4 \mathrm{~A}$ \\
\hline I Set rele & $4,6 \mathrm{~A}$ & $5,2 \mathrm{~A}$ \\
\hline Td (SI) & 0,34 & 0,3 \\
\hline Tact (detik) & 1,36 & 1,18 \\
\hline Kurva & $\mathrm{SI}$ & $\mathrm{SI}$ \\
\hline
\end{tabular}

Berdasarkan perhitungan setting Rele Arus Lebih (OCR) pada sisi $150 \mathrm{kV}$ Transformator 3 didapatkan waktu tunda rele bernilai $0,34 \mathrm{SI}$ dan nilai waktu kerja aktual rele sebesar 1,36 detik pada saat terjadinya arus gangguan maksimum. Sedangkan hasil perhitungan Setting Rele 
Arus Lebih (OCR) pada sisi $20 \mathrm{kV}$ Transformator 3 didapat waktu tunda rele bernilai $0,3 \mathrm{SI}$ dan nilai waktu kerja aktual rele sebesar 1,18 detik pada saat terjadinya arus gangguan maksimum.

\subsection{Koordinasi Setting OGS dan OCR di Tranformator 3 Gardu Induk Pesanggaran \\ Berdasarkan hasil perhitungan OGS} (Over Generator Shedding) dan OCR (Over Current Relay) di Transformator 3 dapat di tampilkan pada Gambar 2.

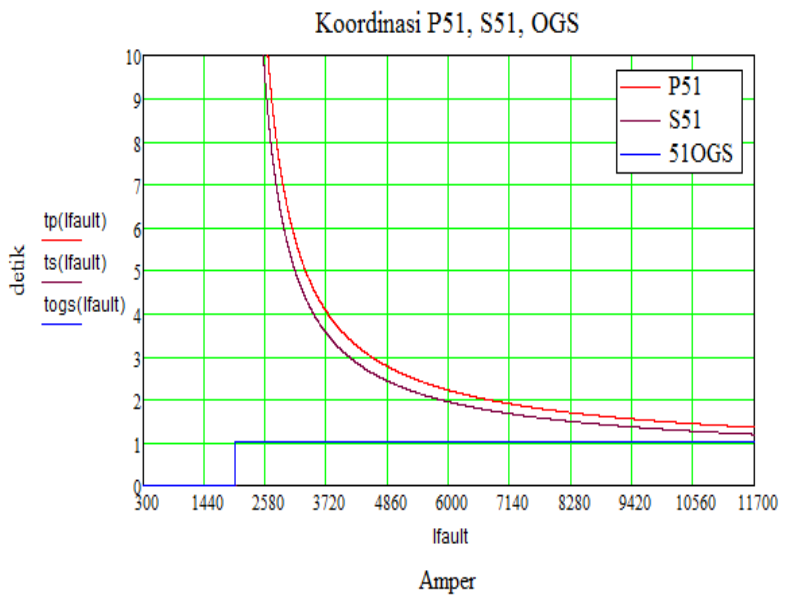

Gambar 2. Grafik koordinasi hasil Perhitungan setting OGS dan OCR

\begin{abstract}
Koordinasi antara OGS dan OCR dimana OCR akan bekerja untuk melindungi Transformator 3 dari arus gangguan akibat hubung singkat yang terjadi sedangkan untuk OGS akan bekerja untuk melindungi Transformator 3 agar tidak bekerja melebihi batas operasi kerja Transformator 3. Setting waktu kerja OCR yang lebih tinggi dari OGS menyebabkan OCR tidak trip bersama-sama dengan OGS ketika terjadi gangguan. Dari gambar 2 dapat dilihat koordinasi setting rele yang baik karena tidak terdapat perpotongan kurva antara OGS dan OCR, sehingga sistem pengamannya bekerja sesuai dengan tugas rele pengaman tersebut.
\end{abstract}

\section{SIMPULAN}

Dari hasil perhitungan yang telah dilakukan didapat setting arus OGS tahap 1 sebesar 1600 A dengan waktu kerja 2 detik, tahap 2 sebesar 1700 A dengan waktu kerja 1,5 detik dan tahap 3 sebesar $1800 \mathrm{~A}$ dengan waktu kerja 1 detik. Karakteristik OGS yang dipakai adalah definite. Berdasarkan perhitungan setting Rele Arus Lebih (OCR) pada sisi 150 kV
Transformator 3 didapatkan setting arus $277 \mathrm{~A}$, waktu tunda rele bernilai 0,34 SI dan nilai waktu kerja aktual rele sebesar 1,36 detik. Sedangkan untuk hasil perhitungan Setting Rele Arus Lebih (OCR) pada sisi 20 kV Transformator 3 didapat setting arus 2078,4 A, waktu tunda rele bernilai $0,3 \mathrm{SI}$ dan nilai waktu kerja aktual rele sebesar 1,18 detik. Karakteristik Rele Arus Lebih (OCR) yang dipakai adalah inverse. Untuk koordinasi setting rele OGS (Over Generator Shedding) dan OCR (Over Current Relay) hasil perhitungan di Transformator 3 sudah baik karena sistem pengamannya bekerja sesuai dengan tugas rele pengaman tersebut.

\section{DAFTAR PUSTAKA}

[1] I. W. Rinas, "Studi Analisis Losses Dan Derating Akibat Pengaruh THD Pada Gardu Transformator Daya Di Fakultas Teknik Universitas Udayana," Jurnal Teknologi Elektro, Vol. 11, No. 1, May 2012.

[2] PT PLN (Persero), Buku Pedoman Pemeliharaan Proteksi Dan Kontrol Transformator. Jakarta : PT PLN (Persero), 2014.

[3] P. Sigid, Analisa Pengaruh Pembebanan Terhadap Susut Umur Transformator Tenaga. Universitas Diponegoro. Semarang, 2009.

[4] M. T. Alawiy, Proteksi Sistem Tenaga Listrik Seri Rele Elektromagnetis. Universitas Islam Malang. Malang, 2006.

[5] I. Baskara, I. W. Sukerayasa, and W. G. Ariastina, "Studi Koordinasi Peralatan Proteksi OCR Dan GFR Pada Penyulang Tibubeneng," Jurnal Teknik Elektro, vol. 14, no. 2, pp. 5056, 2015.

[6] A. Subakat, Studi Pengaruh Pemasangan Load Shedding di Gardu Induk Pemecutan Kelod dan Gardu Induk Nusa Dua Terhadap Kontinyuitas Aliran Daya Gardu Induk Nusa Dua. Tugas Akhir Universitas Udayana, Jimbaran, 2014.

[7] P. Kadarisman and S.N. Wahyudi, Proteksi Sistem Distribusi Tegangan Menengah. Jakarta : PT.PLN (Persero), 2009.

[8] E. Putra, "Analisis Koordinasi Setting Relay Pengaman Akibat Uprating Transformator Di Gardu Induk Gianyar," E-J. SPEKTRUM, vol. 2 No. 2, Jun. 2015. 
[9] C. Bagus, Analisa Implementasi Rele OGS sebagai proteksi sistem $500 \mathrm{kV}$ di Suralaya - Balaraja dan Suralaya Cilegon Dengan Menggunakan Etap 6.0. Jakarta, 2012. 